\title{
Radiation Effects on Surface Micromachined Comb Drives and Microengines
}

\author{
L. P. Schanwald ${ }_{*}^{*}$ J. R. Schwank ${ }_{* *}^{* *}$ J. J. Sniegowski ${ }^{*}$ D. S. Walsh, N. F. Smith, K. A. Peterson, \\ M. R. Shaneyfelt ${ }^{*}$, P. S. Winokur ${ }^{* *}$, J. H. Smith ${ }^{*}$, and B. L. Doyle *IEEE Member, **IEEE Fellow \\ Sandia National Laboratories, P.O. Box 5800, MS 0972 Albuquerque, NM 87185-0972
}

\begin{abstract}
Surface micromachined comb drive and microengine fluence thresholds and failure modes were investigated in $\mathrm{x}$-ray, electron, and proton total-dose environments. Very high fluence levels were necessary to induce motion degradation or lockup for normal device biasing or operation. For the abnormal biasing of ungrounded or partially grounded dice, significantly lower fault thresholds were observed, but still in a medium or high fluence range.
\end{abstract}

\section{INTRODUCTION}

Microelectromechanical systems (MEMS) are rapidly developing into viable commercial, satellite, and military applications as two classes; sensors and actuators [1-3]. For many applications, performance reliability due to radiation effects on both classes of devices is of high interest. Surface micromachined capacitive sensors have been previously tested for radiation sensitivity $[4,5]$. Both total dose and single event effects were explored using these MEMS accelerometers. They show change in accelerometer output signals by exposing the capacitive sense element of the devices to protons, heavy ions, and Co-60 irradiation. Output signal shifts and changes indicating lockups were measured. The processing electronics on the same die were evaluated separately for its own response to radiation. Little other radiation work on MEMS sensors or actuators has been published.

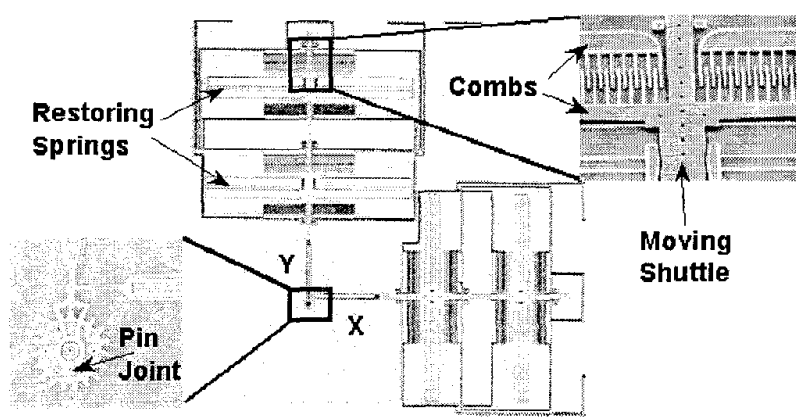

Figure 1. A microengine showing two comb drives and their linkage arms. The linkage arms connect to a small drive gear in the left/bottom of the figure [7].

This study evaluates the mechanical and electrical performance of MEMS comb drive and microengine actuators in total dose radiation environments. Comb drives are reciprocating linear electrostatic devices and are key building blocks for the MEMS microengine shown above in Fig. 1. The detailed inset of combs in Fig. 1 illustrates the inter- digitated comb teeth that create electrostatic force utilized for linear motion. Individual comb drives and microengines were evaluated as mechanical units, enabling us to assess directly the effects of irradiation on the mechanical and electrical response of each. Devices were processed using Sandia's SUMMiT process [6]. Figure 2 illustrates the materials and thickness involved in the SUMMiT process. This process is a series of depositions of four polysilicon layers (MMPoly0MMPoly3) with three sacrificial oxide layers (SACOX1SACOX3) deposited in between them. The sequential masking and etching of these layers combine to form a three dimensional polysilicon device attached to a $\mathrm{Si}_{3} \mathrm{~N}_{4} /$ oxide platform, after a final etch release of the three sacrificial oxide layers. Chemical mechanical processing (CMP) of the polysilicon layers is performed to improve the flatness of the structures.

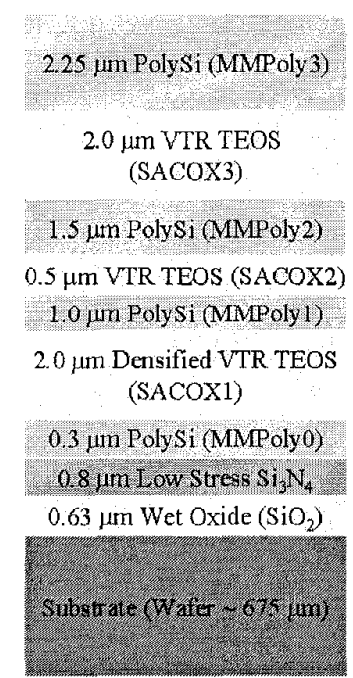

Figure 2. Four layer poly-process structure (SUMMiT [6]), poly0 and substrate are ground unless poly0 is isolated for a comb-drive base, microengine drive contact pad, etc.

The ground plane poly0 layer acts as a screen to charging in the insulator layers under it. This was observed effective in reducing the radiation sensitivity of capacitive sensors in accelerometers [4]. In the layout of SUMMiT produced MEMS comb drives, small portions of the nitride are necessarily left exposed and unscreened by poly0 to electrically isolate the separate regions of the actuator.

\section{RELIABILITY AND RADIATION EFFECT ISSUES}

Recent studies [7-9] of wear and reliability in MEMS comb drives and microengines, under normal operating 
environments, have identified adhesive (Fig. 3) and abrasive wear as failure mechanisms in the constant failure rate portion of the characteristic lifetime or "bathtub" curve. The large sample sizes produced precise estimates of normal and frequency dependent failure rates for single and bimodal defect populations. The adhesive force illustrated in Fig. 3 is a progressive "aggregate" (varied size) type of particle formation and reattachment to both sides of contacting surfaces that have sufficient asperities (deviations from flatness or surface roughness). A microweld is a fusion of two surfaces normally at the asperity points. These microwelds can increase friction and depending on their size can be either temporary or permanent. Increased friction will affect the performance of a comb drive or other actuator surfaces. Abrasive wear is a cutting or material removal of the surface increasing the roughness.

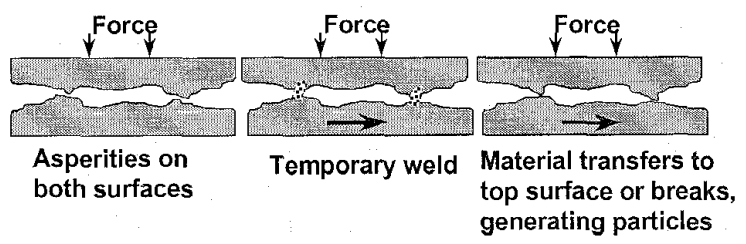

Figure 3. Adhesive wear component of sliding friction failure mode [8].

For reliability considerations, radiation exposures of MEMS may appear to be a stress test, or accelerated stress environment. This assumption is valid only if radiation is a factor in failure of a normal reference environment [7-9]. Because of potentially different root mechanisms leading to failure, radiation induced charging should not be considered an acceleration of normal failure modes for these actuators.

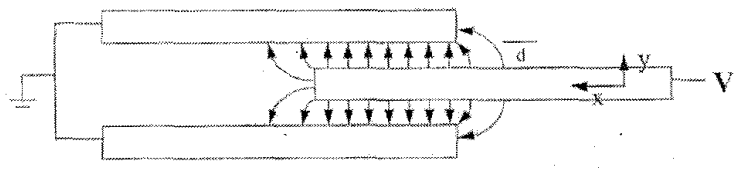

Figure 4. Comb-drive electrostatic forces [3].

Two types of reliability failures in comb drives, related to a standard operating environment, are lateral [9] (adjacent comb teeth) and linear (comb teeth at end of travel) electrostatic clamping. The electrostatic forces related to comb drive motion and these failures are illustrated in Fig. 4 . The electrostatic lines of force shown in Fig. 4 between interdigitated comb teeth illustrato how the lateral forces botrresn comb teeth cancel out but can be unstable (if not limited). The end line forces at the tips of the teeth add to create the net force, $F_{C F}$. This net force moves the teeth in attraction only along the teeth length for any polarity net voltage difference. The force does not depend on the relative lengthwise position between the teeth and is constant for a constant voltage difference. These failures have been largely corrected by design effort [6], but may become aggravated by radiation effects. The total force on a comb drive, $F_{C F}$, is given by

$$
F_{C F}=n \varepsilon_{0} \frac{t}{d} V^{2}-F_{\text {Spring. }}-F_{\text {Friction }}
$$

where $n$ is the number of teeth, $\varepsilon_{0}$ is the dielectric constant for the teeth gap, $t$ is the tooth thickness, $d$ is the inter-tooth lateral gap. The first term of Eq. 1 results from electrostatic attraction, and the last term results from friction and both can result in comb drive and microengine failure $[7,9,10]$.

Potentially the electrostatic attraction and friction can be aggravated by charging effects and may also be sensitive to radiation. Radiation-induced charging may enhance or contribute to microwelding, electrostatic clamping, and or wear processes between two surfaces where small gaps or contact occurs. In a microengine, sub-micron gaps exist between gear hub and drive gear and gear pin and drive gear. A significant radiation-induced charging potential between polysilicon layers may be developed at these locations.

If radiation-induced microwelding were to occur, an estimate of maximum gap initiating breakdown may be calculated. Breakdown fields for air are much lower than that for the polysilicon native oxide or thin chemical oxide $(30 \mathrm{kV} / \mathrm{cm}$ compared to $1-10 \mathrm{MV} / \mathrm{cm}$ ). At normal comb tooth gap spacing ( 1 to $2 \mu \mathrm{m})$ and operating voltages $(30-100 \mathrm{~V})$ air breakdown would occur, following Paschen's Law, if not for the native oxide low conduction. A maximum field for native oxide breakdown, maximum $\mathrm{V}_{\mathrm{Ox}}$, to start (an assumed precursor of microwelding) can be calculated by solving Eqs. (2) and (3) simultaneously [12], while reducing the gap d.

$$
\begin{aligned}
V_{O X} & =\frac{\varepsilon_{0}}{\varepsilon_{O X}} \frac{t_{O X}}{d} V_{A i r} \\
V_{\text {Total }} & =V_{A i r}+2 V_{O X}
\end{aligned}
$$

For Eqs. (2) and (3) $\varepsilon_{0 X}$ is the native oxide dielectric constant, $t_{O X}$ is the native oxide thickness, $V_{O X}$ is the voltage across the native oxide, and $\mathrm{V}_{\mathrm{Air}}$ is the voltage across the tooth lateral gap d.

If initial conditions are $\mathrm{V}_{\text {Total }}=80 \mathrm{~V}$ (a typical operating voltage) and $t_{O X}=10 \mathrm{~nm}$, then the electric fields across the air gap $\xi_{\text {Air }}$ and native oxide $\xi_{\text {NatOx }}$ can be found in Table 1. Depending on the defects in the polysilicon native oxide formed on these structures, it is possiblo for it to brealsdown somewhere in the range of 1 to $10 \mathrm{MV} / \mathrm{cm}$ at corresponding gaps of $0.2 \mu \mathrm{m}$ to less than $0.03 \mu \mathrm{m}$. These small gaps are not normally experienced in the comb-drive's teeth range of motion. Portions of the microengines where small gaps or contact between two surfaces are experienced (comb-drive shuttle guides, microengine shuttle, linkage, and gear dimples, and gear hubs and gear pins) do not normally incur large operating voltages across them (they are, in theory, at the same potential). Shuttle guide gaps are $0.5 \mu \mathrm{m}$ or less and on either side of the shuttle detail shown in Fig. 1. Shuttle, 
linkage, and gear dimples are 1-3 $\mu \mathrm{m}$ diameter bumps on the bottom of these moving parts to prevent large surfaces coming in contact and permanent adhesion forming.

Table 1. Maximum native oxide fields for various comb tooth gaps, $\mathrm{V}_{\text {total }}=80 \mathrm{~V}$, and $\mathrm{t}_{\mathrm{ox}}=100$ Angstroms.

\begin{tabular}{|c|c|c|}
\hline $\operatorname{Gap}(\mu \mathrm{m})$ & $\xi_{\text {Air }}(\mathrm{MV} / \mathrm{cm})$ & $\xi_{\text {NatOx }}(\mathrm{MV} / \mathrm{cm})$ \\
\hline 1.00 & 0.796 & 0.204 \\
\hline 0.200 & 3.90 & 1.00 \\
\hline 0.0360 & 19.5 & 4.99 \\
\hline
\end{tabular}

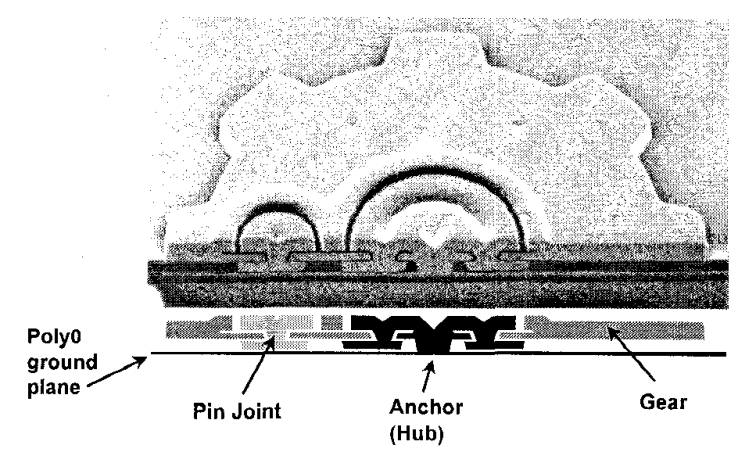

Figure 5: Microengine gear cross section [8].

A gear hub and pin joint gap can be seen in the Fig. 5 cross section. Electrical isolation of a microengine's drive gear is possible by similar small gaps (in the gear hub and pin joint) from both the ground plane (poly0) and a grounded linkage arm (connected to the pin joint in Fig. 5). This is the only electrically isolated polysilicon structure (assumed by native oxide and small gaps) that may be affected by radiationinduced charging. All others have a direct connection, through one of the polysilicon layers, to a driving pad connection or the ground plane poly0. During drive gear movement, normal wear mechanisms [8] create electrical contact of the drive gear to poly0.

Capacitance measurements of the comb inter-tooth (air gap) or poly0-substrate $\left(\mathrm{SiO}_{2} / \mathrm{Si}_{3} \mathrm{~N}_{4}\right.$ in Fig. 2) structures might conveniently measure their induced charging from radiation. Although a charged insulator directly under poly0 is screened, measuring its induced charge may give an idea of charging experience by exposed nitride as well. Since both of these capacitances are connected in parallel to the only available contact point (drive signal input), it is useful to know the relative magnitudes of each. Both comb teeth $\mathrm{C}_{\mathrm{CD}}$, and poly0substrate capacitance $\mathrm{C}_{\mathrm{OXP} 0}$, can be calculated from

$$
\begin{aligned}
& C_{\mathrm{CD}}=2 n \frac{\varepsilon_{0} t(L-x)}{d}, \\
& C_{\text {OYPo }}=\frac{A_{\mathrm{Comb}}}{\frac{t_{\mathrm{SiO}_{2}}}{\varepsilon_{\mathrm{SiO}_{2}}}+\frac{t_{\mathrm{Si}_{3} \mathrm{~N}_{4}}}{\varepsilon_{\mathrm{Si}_{3} N_{4}}}},
\end{aligned}
$$

where $L$ is length of comb teeth, and $x$ is length gap (end of tooth to opposite comb). $A_{\text {comb }}$ is the sum of comb base, probepad, and trace areas. A comb base is the poly0 anchor of the upper comb structure (non-moving) of the insert in Fig. 1.

For a standard comb drive, the total inter-tooth and poly0substrate capacitance $\mathrm{C}_{\mathrm{CD}}$ and $\mathrm{C}_{\mathrm{OXP0}}$ are found to be $6.1 \cdot 10^{-14}$ and $2.6 \cdot 10^{-12} \mathrm{~F}$, respectively. Their ratio is almost 40 and suggests for comb-drive inputs, the poly0-substrate capacitance will be dominant.

In addition to the comb capacitance, two other mechanical performance parameters were used to assess radiation-related effects. Resonant frequency spectrum was used for comb drives while drive gear temporal analysis was used for a microengine $[8,9]$. The first mechanical performance parameter of resonant frequency spectrum is illustrated in Fig. 6. These responses show the relation of $\mathrm{Q}$ factor to actuator force magnification. $Q$ factor is defined as the peak resonant frequency divided by the $3-\mathrm{dB}$ bandwidth for a resonant spectrum (electrical or mechanical). The comb-drive force magnification factor is the ratio of force change in a mechanical device at a particular frequency relative to the force for the same driving signal at zero frequency $F_{n}$. From Fig. 6 the change in actuator or resonant device force can be determined from the change in resonant spectrum. Thus the force changes in a mechanically resonant device resulting from radiation, like a comb drive, can be quantified. The microengine drive gear angle rate produces a temporal profile of any gear-related anomalies.

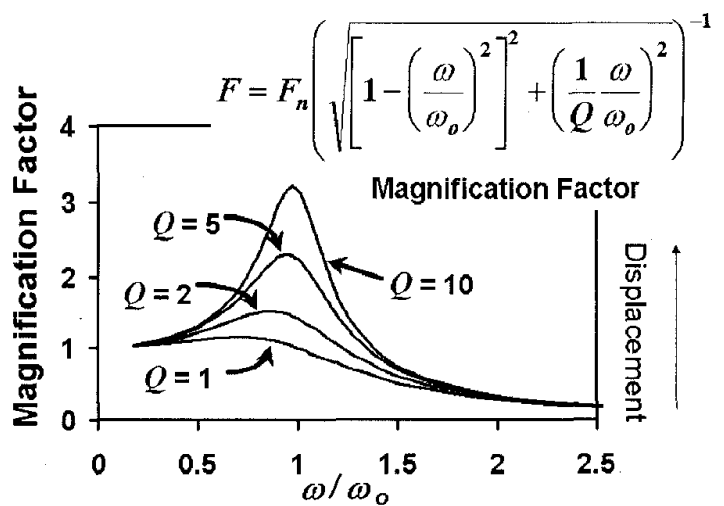

Figure 6. Typical resonant frequency spectrum curves showing magnification factor related to $Q$ factor [8].

\section{EXPERIMENTAL DETAILS}

In this work sample sizes ( 1 to 2 each with a non-irradiated control) were tested and evaluated for estimating the fluence thresholds and observing failure modes. The time involved in manually measuring the comb drive frequency spectrum response and the availability of test parts after eliminating infant mortality, influenced the use of small sample sizes for radiation effects analysis. The small sample sizes resulted in a reduced measurement precision for the fluence thresholds effecting degradation, and no measure of radiation failure rate 
was attempted. The mechanical measurements on test and control samples took significant times ( $\sim 5-10$ minutes each).

The above performance criteria (comb-drive capacitance and resonance and microengine gear analysis), were measured at interval data points in $\log$ step increases of total radiation dose. The microengine drive gear motion degradation was inferred from any measurable deviation from its normal gear angle rate pattern. For the comb drives, changes in motion degradation were inferred from any change in the resonant frequency spectrum. Device lockup was inferred from a microengine drive gear not completing a rotation or a comb drive not moving with normal drive signal.

Devices were exposed to $x$-rays, electrons, and protons. The $x$-ray source consisted of an Aracor model 4100 10-keV system. An x-ray dose rate of $4.4 \mathrm{krad}(\mathrm{Si}) / \mathrm{s}$ was used. The electron source was an Amray model $1850 \mathrm{FE}$ scanning electron microscope (SEM) operated at energies of 5 to 25 $\mathrm{keV}$ and beam currents from 0.1 to $1.0 \mathrm{nA}$, with a typical beam size of 1.5 by $1.0 \mathrm{~mm}$. The proton source was the Sandia tandem van de Graff accelerator facility operated at a beam energy of $2 \mathrm{MeV}$ with beam currents from 0.1 to $3.5 \mathrm{nA}$ and a beam size of 0.5 by $0.5 \mathrm{~mm}$. The range of radiation levels used for exposures is listed in Table $2(1 \mathrm{rad}=100$ $\mathrm{erg} / \mathrm{gram})$. The lowest fluence level listed for electrons of $10^{12} \mathrm{~cm}^{-2}\left(140 \mathrm{krad} \mathrm{SiO}_{2}\right)$ is consistent with equivalent total dose levels for space GPS orbits of approximately $280 \mathrm{krad}$ $\left(\mathrm{SiO}_{2}\right)$ per year. This $280 \mathrm{krad}\left(\mathrm{SiO}_{2}\right)$ per year is an estimate from GPS orbit projections of $5 \mathrm{X}$ total dose of a geostationary orbit (GEO), with only 100 mils Al shielding.

Table2: Ranges for source fluence/dose levels used fluence $\# / \mathrm{cm}^{2}$ (equivalent dose $\mathrm{rad}, \mathrm{SiO}_{2}$ )\}.

\begin{tabular}{|c|l|l|l|}
\hline Levels & X-ray (10keV) & Electron (5-25keV) & \multicolumn{1}{c|}{ Proton (2MeV) } \\
\hline $\min$ & NA(10krad) & $10^{12} \mathrm{~cm}^{-2}(140 \mathrm{krad})$ & $10^{12} \mathrm{~cm}^{-2}(2 \mathrm{Mrad})$ \\
\hline $\max$ & NA(100Mrad $)$ & $4 \cdot 10^{16} \mathrm{~cm}^{-2}(5.6 \mathrm{Grad})$ & $5 \cdot 10^{16} \mathrm{~cm}^{-2}(100 \mathrm{Grad})$ \\
\hline
\end{tabular}

The test matrix consisted of three bias combinations for the comb drive and microengine and exposing them through a series of radiation steps. The three biasing combinations were fully ungrounded (floating), grounding all pins, or setting the device to a driven state. The ungrounded parts were found to be more sensitive to irradiation for all three sources. The exposure levels for the ungrounded (floating) parts were limited between $10^{12} \mathrm{~cm}^{-2}$ and $10^{14} \mathrm{~cm}^{-2}(<\max$ in Table 2). The grounded or driven parts were less sensitive to irradiation and were subjected to the highest levels of radiation as given in Table 2.

The x-ray exposures were full-die exposures. For the protonand electron-beam exposures selected areas of the microengines were irradiated using the previously noted beam sizes $\left(\sim 1 \mathrm{~mm}^{2}\right)$.

The microengine consists of two comb drive actuators (the teeth-like structures in Fig. 1) and linkage arms connecting them to a small drive gear. Individual microengine and combdrive actuators (with the linkage arms removed) were evaluated. The normal operating voltages for the microengine are 60 to $80 \mathrm{VAC}$ amplitude waveforms and $35 \mathrm{VAC}$ for a comb drive (both off resonance with no DC component). Microengines were assessed by video taping a drive gear at high magnification $(500 \mathrm{X})$ and relatively slow rotation $(0.5$ $\mathrm{Hz}$ ). Observable changes in the rotation angle versus time (angle rate) were interpreted as an increase in friction or change in comb-drive forces for the microengine. This data can be used to demonstrate motion degradation (due to increased friction or coulomb forces) or gear lockup (incomplete drive gear rotation)

For the comb drive, resonant frequency spectrum (Fig. 6) was measured. The comb teeth displacement was measured while varying drive frequency at constant drive voltage. Typically a $6 \mathrm{~V}$ sine wave and constant $6 \mathrm{~V}$ DC offset voltage (for driving with one input) was used while measuring the blur envelope (viewed displacement on a video image that shows extent or range of travel) created on the magnified video monitor image. A low driving voltage was used because of the resonance magnification factor. In addition, the comb drives were evaluated for lockup (complete stop).

Capacitance voltage sweeps were measured on comb-drive inputs, relative to ground poly0, by a Cascade( $B$ Summit 12000 low-noise shielded parametric system. An HewlettPackard HP4284 was used with this enclosed probe station as the $\mathrm{C}-\mathrm{V}$ meter. Delays between part exposure and measurement were typically less than one hour and on rare occasion's twelve hours for a late particle exposure. These delays should not have produced significant annealing in the $\mathrm{Si}_{3} \mathrm{~N}_{4}$, where the majority of charge traps were formed.

\section{EXPERIMENTAL RESULTS}

The first $x$-ray exposures were performed on two grounded packaged dice, each with one microengine and one resonant comb drive, and one control. A resonant comb drive is a specially designed structure for characterization of comb-drive properties and $\sim$ half the size of a standard comb drive (microengine building block).

In the case of the microengine, the gear angle rate (measured at $0.5 \mathrm{~Hz}$ drive signal frequency) and $\mathrm{C}-\mathrm{V}$ results are shown in Figs. 7 and 8 , respectively. The line showing perfect rotation illustrates a constant "ideal" change in angle with time, and one complete revolution of the drive gear. A deviation from the ideal case exists because of non-uniform friction with gear angle and drive signals not fully optimized for the individual microengine. In Fig. 7 the point of potential degradation, as indicated by a change in gear angle rate, is clearly evident. Logarithm steps in radiation dose were used to expose this microengine from $3 \cdot 10^{6}$ to $10^{8} \mathrm{rad}\left(\mathrm{SiO}_{2}\right)$, and showed a steady change in the potential radiation-induced degradation. This degradation was observed in the second test sample and no change was measured for the control.

A second test on a single microengine and control was performed to try to reproduce this radiation effect. The test 
part was subjected to identical radiation exposures, but was floating instead of grounded during irradiations. The floating test die condition should exhibit higher radiation sensitivity.

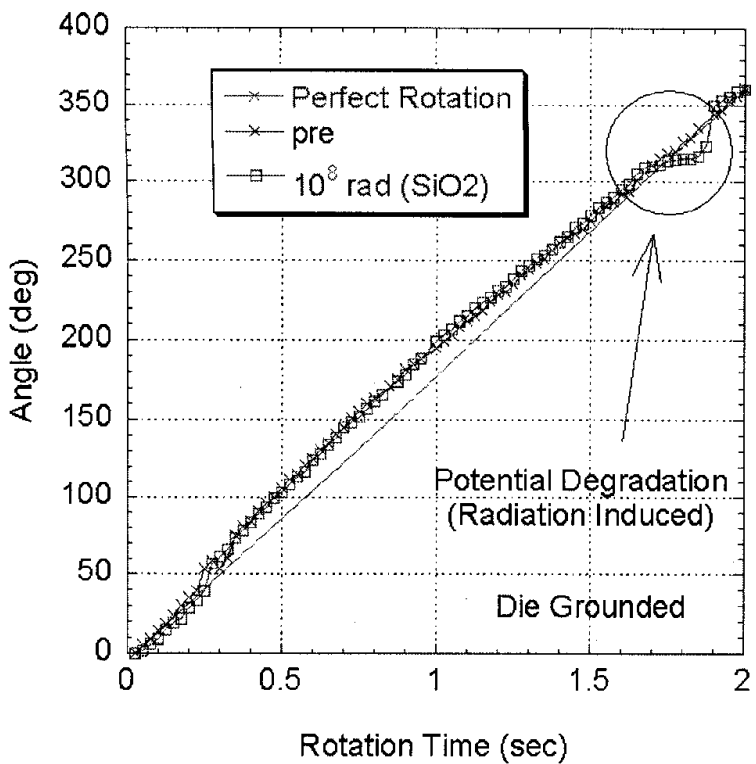

Figure 7. Microengine gear data, $x$-ray dose, all pins grounded.

The results for the second test were similar changes in the drive gear angle rate, but smaller. It was also observed that the control microengine exhibited identical changes in its drive gear angle rate, thus suggesting no radiation-induced effect. Potentially this may be normal wear effects, as found from previous studies $[9,10,11]$. Or the difference in results may indicate a very broad radiation sensitivity range where this effect begins.

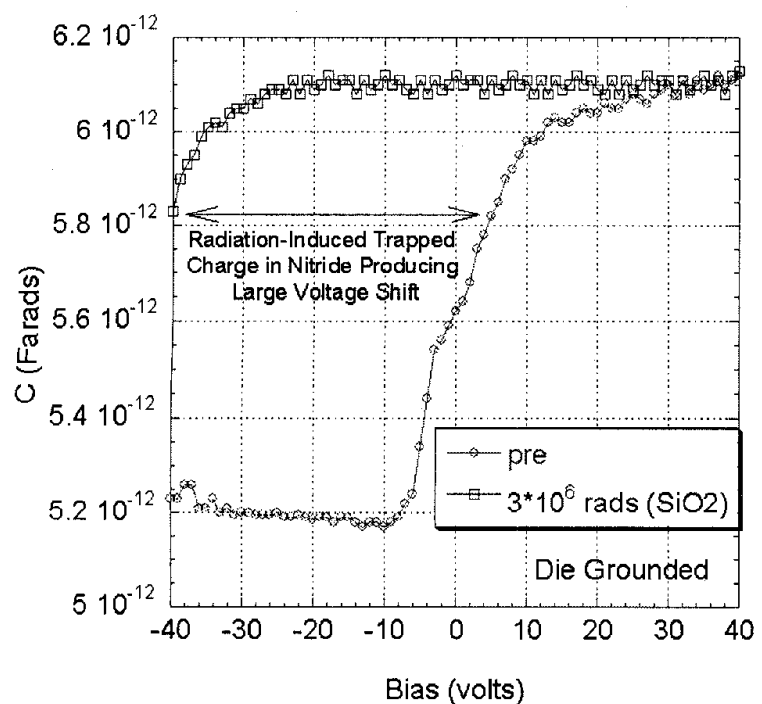

Figure 8. Standard comb drive $\mathrm{C}-\mathrm{V}$ data, $\mathrm{x}$-ray dose, all pins grounded.

Resonant frequency response for the grounded resonant comb drive (same die as Fig. 7), and latter the floating standard comb drive, showed no change with the total dose levels starting at $3 \cdot 10^{6}$ to $10^{8} \mathrm{rad}\left(\mathrm{SiO}_{2}\right)$. On the same comb drive C$\mathrm{V}$ data was measured at one of the drive pads. No bias was applied to the opposite comb-drive pad and left floating. The $\mathrm{C}-\mathrm{V}$ results (Fig. 8) show a large buildup of trapped positive charge likely in the $\mathrm{Si}_{3} \mathrm{~N}_{4}$ /oxide insulator between poly0 and the substrate. These areal densities were measured to be approximately $2.2 \cdot 10^{12} \mathrm{~cm}^{-2}$ for the x-ray dose of $3 \mathrm{Mrad}$ $\left(\mathrm{SiO}_{2}\right)$.

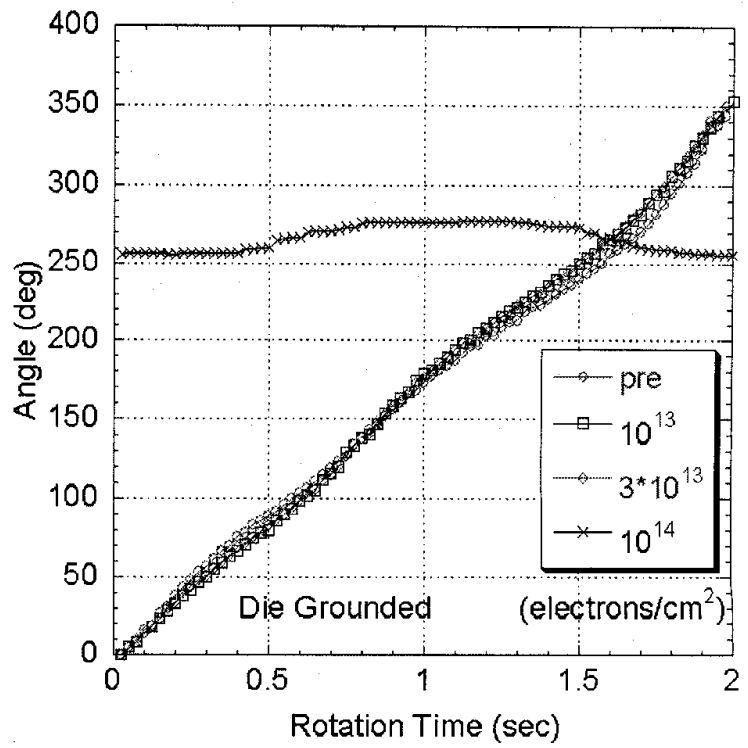

Figure 9. Microengine drive gear, ebeam fluence, die 1, all pins grounded.

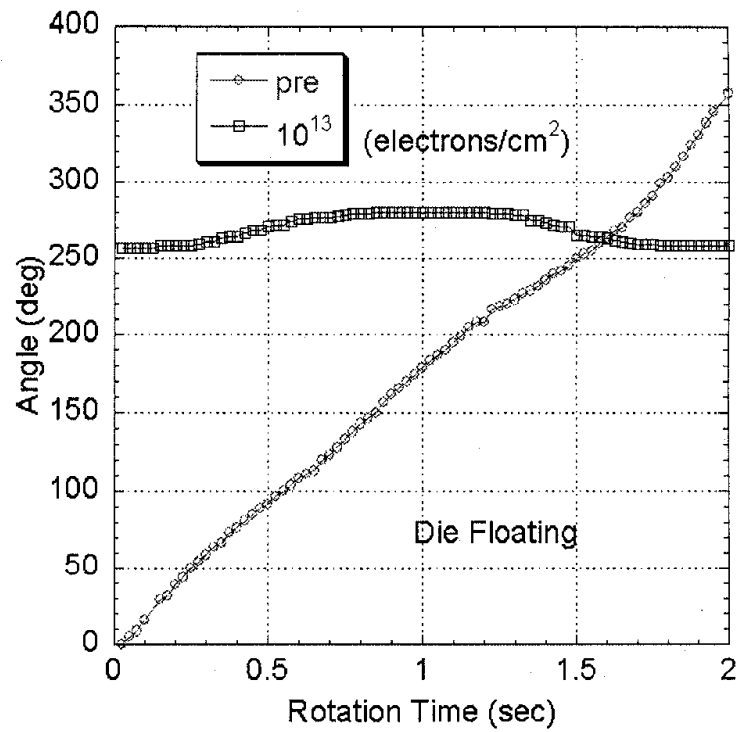

Figure 10. Microengine drive gear, ebeam fluence, die 2, all pins floating.

Angle rates for electron exposures are shown in Figs. 9 and 10 , representing one complete drive gear revolution. Two separate packaged dice were irradiated, each containing two working microengines and two mechanically isolated standard 
comb drives. For Fig, 9 (all pins grounded), electron exposures of $10^{13}$ and $3 \cdot 10^{13} \mathrm{~cm}^{-2}$ show normal operation, i.e. an increase in angle with time. Lockup occurred at an electron exposure of $10^{14} \mathrm{~cm}^{-2}$ as indicated by the reduction in gear movement to a few degrees. For Fig. 10 (all pins floating), lockup occurred at an electron exposure of $10^{13} \mathrm{~cm}^{-2}$ (first level examined). Thus, the data in Fig. 9 and 10 illustrate a decreased sensitivity to radiation for the die grounded when irradiated. This evaluation is based on two test parts and thus no statistical confidence in radiation levels may be assigned, although an order of magnitude difference in sensitivity exists.

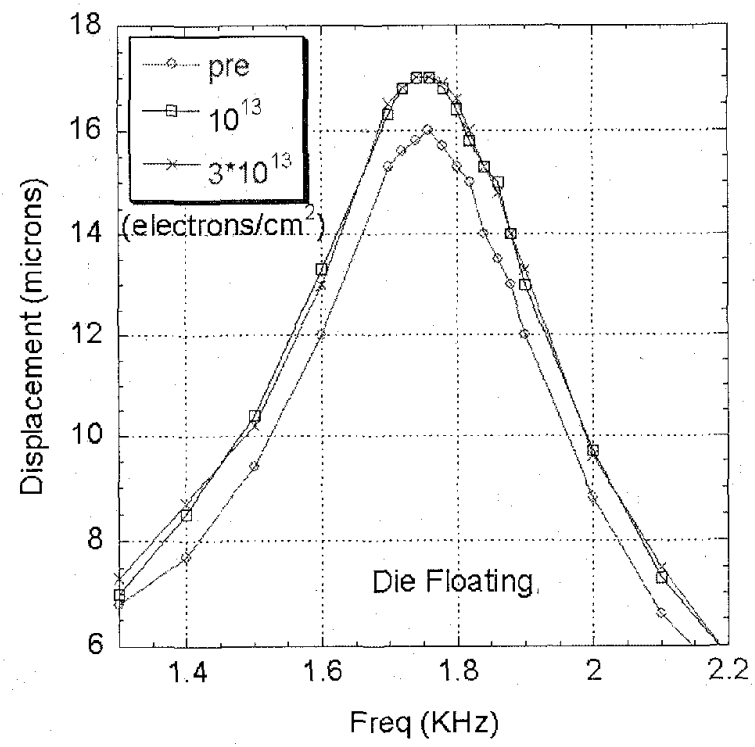

Figure 11. Standard comb-drive resonance for ebeam, $25 \mathrm{keV}$, $1.0 \mathrm{nA}$, and given fluences. die 2 , die floating.

Figure 11 is a resonant frequency spectrum for a mechanically isolated comb drive irradiated with electrons at fluence levels of $10^{13}$ and $3 \cdot 10^{13} \mathrm{~cm}^{-2}$ with the die floating. The comb drive for the data of Fig. 11 was located on the same die as the microengine for the data of Fig. 10. Figure 11 demonstrates radiation-induced changes in resonance. The measurement error for all the resonant frequency data shown is $\sim \pm 0.3 \mu \mathrm{m}$. The resonant response for grounded comb drives (not shown) revealed no change in magnitude or peak frequency for fluence levels up to $10^{14}$ electrons $/ \mathrm{cm}^{2}$. These data show that the comb drives were still functional up to the point where the microengine failed. This implies that the charge buildup in the comb drive is probably not the source of lockup for the microengines irradiated with die floating (Fig. 10), but may relate to charge effects in the drive gear.

Other similarly packaged dice were subjected to electron beam fluences. On one such grounded package a microengine was driven with proper signals to rotate the drive gear at $0.5 \mathrm{~Hz}$ in the SEM chamber while irradiated. It was expected that because of charging effects from the electron beam $(25 \mathrm{keV}$ at $0.1 \& 1.0 \mathrm{nA}$ ) the microengine would soon show signs of degradation or stop functioning completely, by the SEM realtime image. After exposing different parts of the running microengine (comb drives, gear, etc.) for an extended period of over two hours total (equivalent to a total fluence of $~$ $4 \cdot 10^{16}$ electrons $/ \mathrm{cm}^{2}$, for beam sizes of 0.01581 to $195 \times 10^{-6}$ $\mathrm{cm}^{2}$ used), no visible signs of motion degradation were apparent.

On the same die a resonant comb drive had one of its two drive pads bonded out and grounded, but the other was left floating. It was also exposed directly, but for a much shorter total time of approximately 30 minutes, and corresponding total fluence of $\sim 4 \cdot 10^{14}$ electrons $/ \mathrm{cm}^{2}$ (for beam size of $0.0158 \mathrm{~cm}^{2}$ used). Its subsequent resonant frequency response exhibited hysteresis and asymmetric behavior that suggested significant charging occurred. This hysteresis and asymmetry may have resulted from spring fatigue, so a second comb drive was similarly half grounded and exposed to electrons as a test for the same effect.

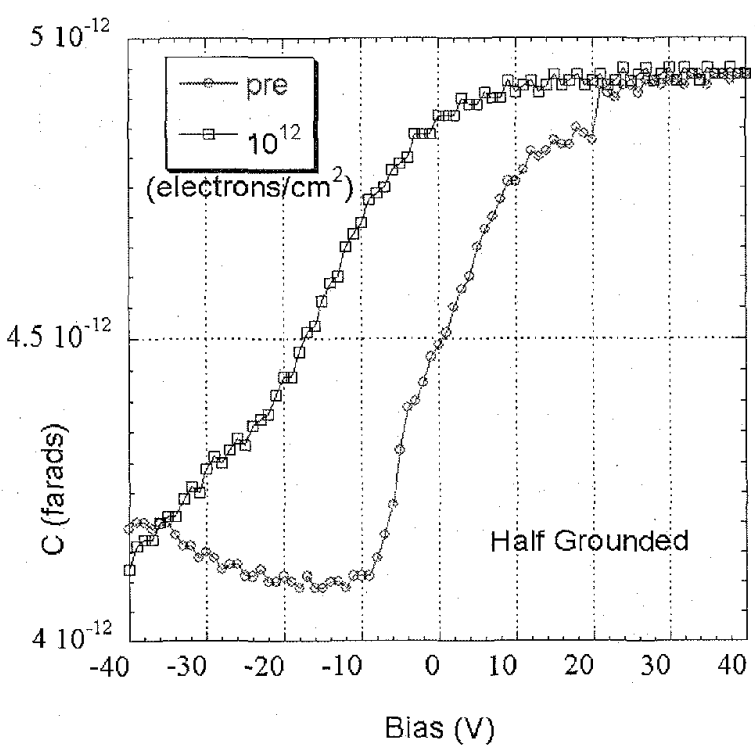

Figure 12. C-V data for standard comb drive half-grounded, ebeam fluence data ( $25 \mathrm{keV}, 0.1 \mathrm{nA})$.

A half-grounded standard comb drive was subsequently ebeam irradiated and characterized. Its $\mathrm{C}-\mathrm{V}$ data in Fig. 12 were measured at the pin that was grounded during radiation. The large buildup of trapped positive charge $\left(7.9 \cdot 10^{11} \mathrm{~cm}^{-2}\right)$ is similar, but less than that shown in Fig. 8 for x-ray dose. Its resonant frequency response was not measured because it locked up (permanently) at the first fluence level of $10^{12}$ electrons $/ \mathrm{cm}^{2}$. The lock up occurred in a linear clamp with the teeth run all the way to the end of travel. This permanent lockup at end of travel indicates a significant attractive force, relative to that of the spring and friction (Eq. (1)). It is inferred that asymmetric charging in the half-grounded device produced this force. Subsequent SEM examination revealed a contact point between a comb tooth and comb base at its end of travel and the nitride strip under it. Other similar linear clamps on half-grounded comb drives have resulted in observable point contacts, and associated distorted $\mathrm{C}-\mathrm{V}$ data and significantly increased conductance through the $\mathrm{SiO}_{2} / \mathrm{Si}_{3} \mathrm{~N}_{4}$ (from micro-Siemens to fractions of milliSiemens). 


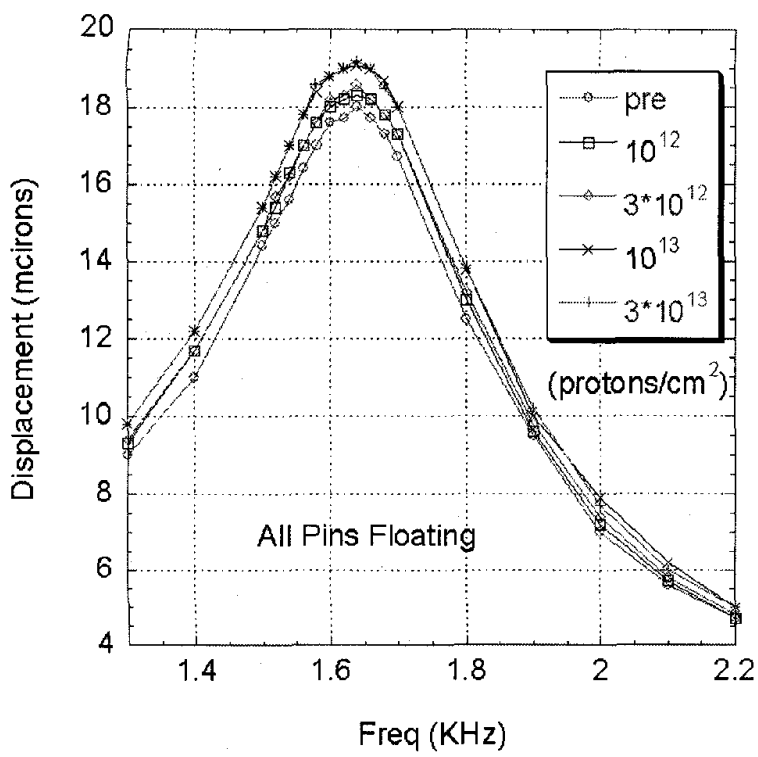

Figure 13. Floating standard comb drive, proton fluence data, die floating.

Proton irradiations also produced an increase in resonant frequency response magnitude of a standard comb drive. A feature of this data is the clear observation of a progressive increase in the resonance magnitude and associated force with radiation level (Fig. 13). This contrasts with an identical standard comb drive on the same die that was not irradiated directly, and showed no change in resonant frequency magnitude (behaved like a control).

In addition to irradiating grounded and ungrounded test dice at the lower proton fluence ranges, a running standard comb drive was exposed to a proton beam. A sine wave signal that produced full range motion at $0.5 \mathrm{~Hz}$ was input to the comb drive while being irradiated. This produced a continuous realtime running test; similar to the one described above for electron exposure of a microengine and comb drive. A proton current of $3.5 \mathrm{nA}$ was used, and for an extended exposure of approximately 10 minutes, no noticeable degradation in performance of the comb drive was observed by magnified video data.

The drive gear behavior shown in Fig. 14 exhibits lockup at a total fluence level of $10^{13}$ protons $/ \mathrm{cm}^{2}$. Unlike the data shown in Fig. 9 for electron exposures, these show a larger change in drive gear rotation pattern with each radiation level, but a lockup failure at the same gear angle.

Motion degradation or failure (lockup) of microengine drive gears had three basic forms. The first was a progressive increase in small deviations from smooth motion (Fig 7). A second observed degradation was a change from smooth circular motion to a smooth half-circular motion followed by a fast (jerky) recovery motion to the starting point. This was most likely due to a malfunction of the left/right comb drive (no force in $1 / 2$ motion of left/right comb drive). The last type of observed degradation was a complete lockup of gear motion (limited to a small angle range of a few degrees), demonstrated in Figs. 9, 10, and 14. It was observed that the motion limited to a few degrees was not due to "slop" in the gear hub or pin joint tolerances, but the flex experienced by the left/right linkage arm being bent by the up/down actuator.

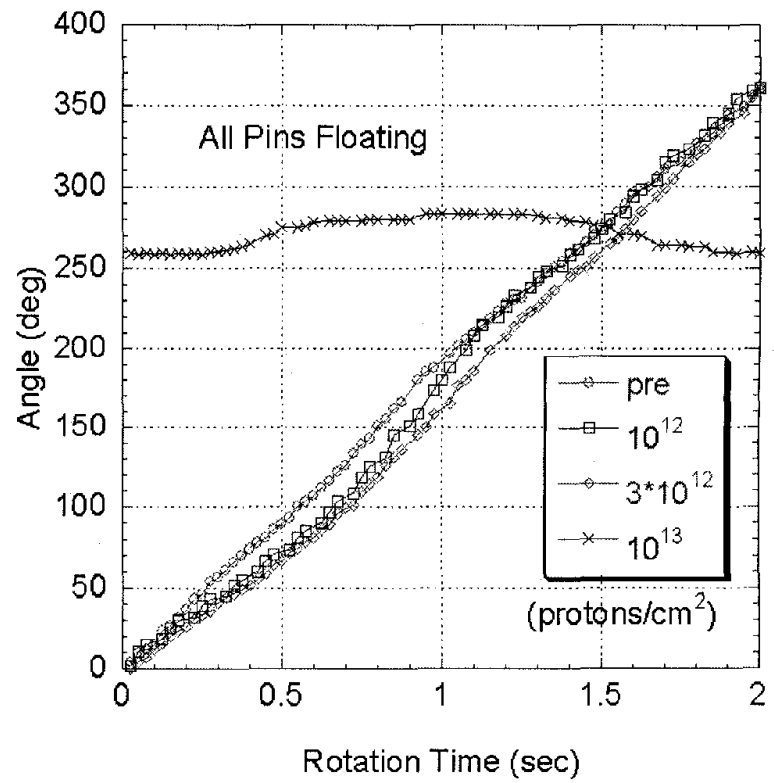

Figure 14. Microengine drive gear angle, proton fluence data, floating comb drive.

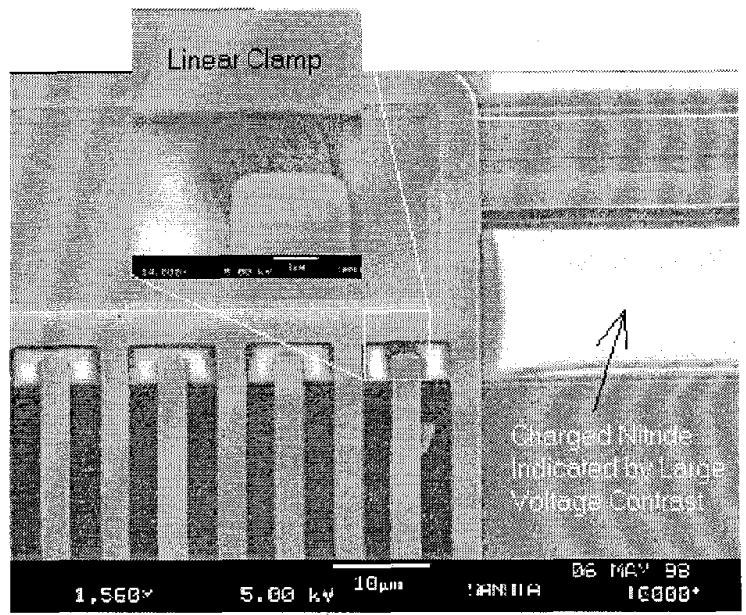

Figure 15. SEM image of comb drive, grounded, ebeam fluence, linear clamp. Voltage contrast in nitride surface.

Closer examination of a locked up microengine, having been grounded during irradiation by electron beam, revealed a linear clamping of the left/right comb drive. This linear clamping of the comb drive is shown in Fig. 15. A portion of the comb structure has broken off in this case and is touching the comb base and the exposed nitride strip below it (probably attracted to the exposed nitride charge). Another tooth of the same comb drive was found in full contact with the opposite comb base. 


\section{DISCUSSION}

The biasing or grounding of an actuator had the biggest influence on radiation hardness. Drive signal biasing of these actuators under electron and proton irradiation resulted in full operation into the $10^{16} \mathrm{~cm}^{-2}$ fluences (Grad equivalent dose, $\mathrm{SiO}_{2}$ ). The highly unusual biasing condition of half-grounded standard comb drives showed radiation sensitivities in the fluence level of $10^{12}$ electrons $/ \mathrm{cm}^{-2}(140 \mathrm{krad} \mathrm{SiO}$ equivalent dose). The half-grounded biasing of a comb drive may yield quantified measures of exposed nitride charging around grounded and ungrounded poly 0 planes in the future. This measure would be implemented by finding the threshold where radiation induced linear clamping occurred and calculating the electrostatic force necessary to overcome the spring and friction forces (Eq. 1). A less likely biasing condition of floating and more likely of grounded comb drives resulted in radiation sensitivities of $10^{13}$ and $10^{14}$ electrons $/ \mathrm{cm}^{-}$ ${ }^{2}$, respectively (1.4 and $14.4 \mathrm{Mrad}^{\mathrm{SiO}}{ }_{2}$ equivalent dose). Summarizing the microengine data for electron and proton sources, radiation sensitivities for floating parts were approximately $1 \mathrm{Mrad}\left(\mathrm{SiO}_{2}\right)$, for grounded parts they were approximately $10 \mathrm{Mrad}\left(\mathrm{SiO}_{2}\right)$, and for driven parts they were above the hundreds of $\mathrm{Mrad}\left(\mathrm{SiO}_{2}\right)$.

Initially the only observed radiation effect for x-ray doses, for a grounded microengine, up to $10^{8} \mathrm{rad}\left(\mathrm{SiO}_{2}\right)$, was a slow degradation in gear rate pattern (Fig 7). This effect was not repeatable with a second test and inconclusive to attribute any correlation, or lack thereof, to radiation without much larger sample sizes. The second $\mathrm{x}$-ray test on floating microengines and comb drives revealed a lockup threshold for comb drives of $\sim 3 \cdot 10^{6} \mathrm{rad}\left(\mathrm{SiO}_{2}\right)$.

The radiation sensitivity for a microengine drive gear was dependent on the three bias conditions (floating, grounded, and electrically driven during irradiation). The observed failure modes of jerky half-rotation, and lockup (small angular range of motion) were observed to be largely a result of comb drive related problems (lateral and linear clamping, half function, etc.). It is also possible drive gear issues may be related to some of these failures. The radiation insensitivity of a moving drive gear may be qualitatively explained by radiation-induced charging and microwelding in the gear contact areas (gear hub and pin joint). The electrically driven microengine has a continuously moving drive gear that can be breaking microwelds as they form. The assumption that the drive gear motion reduces large microwelds from forming is supported by the significant decrease in radiation sensitivity to the Grad equivalent dose level (for electron data). This may be examined in the future. It is also possible particulate contamination may have an effect on small gap spacings of the drive gear and hub and pin joint. Testing packaged parts that were sealed with removable glass lids, and detaching the lid only during radiation exposure and testing minimized this.

The common final gear angle for radiation-induced lockups in the microengines (Figs. 9, 10, and 14) is noteworthy. Closer examination of these microengine comb drives by visible microscope at 500X revealed linear and lateral clamping of the left/right comb drive in different forms. What appeared to be particulate microwelding of an end of a comb tooth to a comb base was one observed clamp. Latter SEM examination (Fig.15) revealed a fragmented comb tooth attached to the nitride strip, with a fragment touching the comb base. An SEM of another portion of the same comb drive revealed a classic linear clamp with a tooth fully contacting it's opposite comb base. These observations of two types of clamping in the same part (clamp to nitride strip and end of tooth contact to comb base) may indicate a new failure mechanism induced by radiation. Normal wear linear clamping has been observed by visible microscope and there is no SEM data to indicate whether these are actually full contracts of a tooth end to a comb base or a tooth close to it's end of travel and in contact with the exposed nitride strip below. Another observed failure was a lateral clamp by a fragment from a comb tooth close to it's end of travel, but not over the nitride strip region.

A common failure mode observed for ungrounded comb drives was linear and lateral clamping. Some of the microengines tested were not the latest designs, which have been modified for preventing the lateral clamping. The latest comb-drive designs have resulted in a significant reduction of lateral clamping under normal wear environments, with linear clamping being the main cause of failure for normal microengine wear. Presently, the shuttle comb teeth may come within $\sim 0.25$ to $0.5 \mu \mathrm{m}$ of the non-moving comb structures at their end of travel. Repositioning of the shuttle stop for smaller range of motion or additional modifications like reducing the width of the nitride strip might reduce the linear clamping occurrences from radiation environments.

Another observed radiation effect was an increase in displacement of comb drives in a non-grounded bias arrangement (Figs. 11 and 13), and to a much lesser degree for grounded parts. This increase in displacement was the only other effect observed that was unique to radiation (other effect unique to radiation was linear clamping by charged nitride strip). One likely cause of observed displacement increase was an additional force introduced to the comb-drive force balance Eq. 1 by an unshielded strip of exposed nitride at the end of travel for the comb teeth (see exposed nitride strip in Fig. 15). This effect may be reduced by decreasing the exposed nitride strip width to less than its present $\sim 3-4 \mu \mathrm{m}$. The displacement increase may not be a problem for many applications, but may be for others (for example precise positioning by comb drive alone). The increase in magnitude and change in linear force $\left(\sim 71 \cdot 10^{-9} \mathrm{~N}\right.$ of total $1.28 \cdot 10^{-6} \mathrm{~N}$ using spring constant of $0.071 \mathrm{~N} / \mathrm{m}$ [7]) is a small percentage of $\sim$ $5.6 \%$. For microengines this will increase the force on the pin joint and gear hub and likely increase the stress on them. Another possible cause of magnitude increase for electron and proton exposures is ion displacement effect producing spring fatigue (macro-mechanical property change in polysilicon spring, e.g. change in spring constant).

For electrical reliability considerations, some additional observations can be made. The measured comb drive 
capacitances agree well with those calculated above for the poly0-substrate of $\sim(3.3$ to 6.2$) \cdot 10^{-12} \mathrm{~F}$ and $2.6 \cdot 10^{-12} \mathrm{~F}$ respectively. The large variation in measured $\mathrm{C}_{\mathrm{ox}}$ may be a result of a large $\mathrm{Si}_{3} \mathrm{~N}_{4}$ thickness variability (inter and intra fabrication lot). The relative agreement between measured and calculated estimates for $\mathrm{C}_{\mathrm{ox}}$ indicate a quantitative way of measuring charging experienced by the $\mathrm{SiO}_{2}-\mathrm{Si}_{3} \mathrm{~N}_{4}$ layer under poly0 is possible. The charging in the exposed nitride regions may be estimated in the future from correlating similar capacitance measurements with quantitative voltage contrast.

The C-V measurements revealed extremely large voltage threshold shifts of approximately 40 volts and greater for $\mathrm{x}$ ray and ebeam irradiations in Figs. 8 and 12. This indicated large charge densities built up in the screened $\mathrm{SiO}_{2}-\mathrm{Si}_{3} \mathrm{~N}_{4}$ layer. Due to the shielding by poly0 of this measured insulator the expected charge densities in the exposed nitride strips would be somewhat larger. The depth of charging for high-energy electrons is illustrated in Fig. 16. The $10-\mathrm{keV} x-$ rays penetration would follow an exponential attenuation reaching into the substrate, and the $2-\mathrm{MeV}$ protons would have a range of approximately $40 \mu \mathrm{m}$. The shifts may be due to the design not being optimized for operation in radiation environments and included some exposed insulators (silicon nitride). Similar voltage threshold shifts in the poly0-substrate capacitance did not effect the resonant frequency response of a biased or grounded comb drive to the same extent.

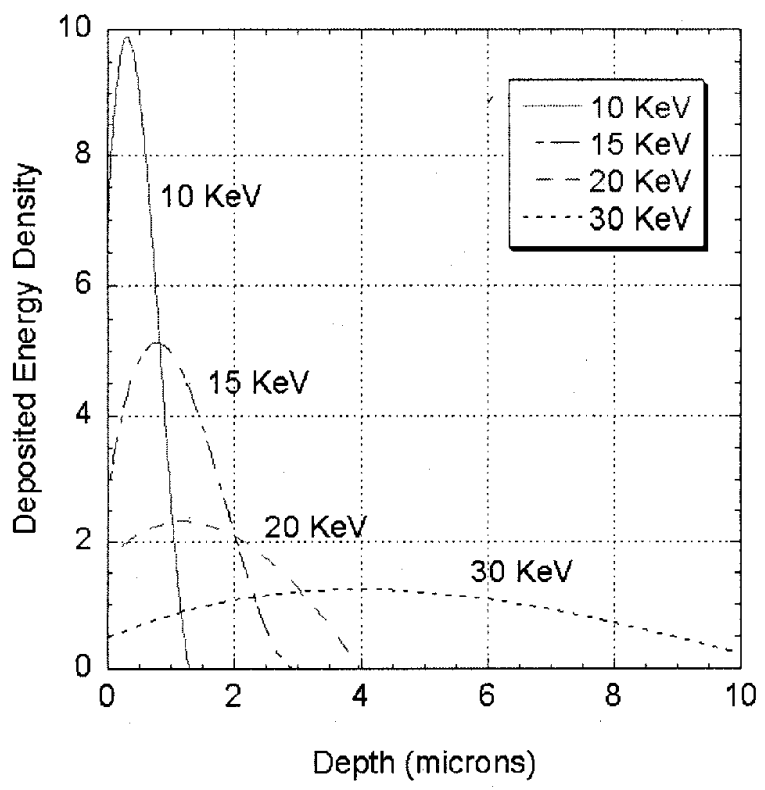

Figure 16. Electron energy distributions for Si [13].

For the data shown in Figures 8 and 12, oxide charge trap densities of approximately $2.2 \cdot 10^{12} \mathrm{~cm}^{-2}$ for the $\mathrm{x}$-ray dose of $3 \mathrm{Mrad}\left(\mathrm{SiO}_{2}\right)$ and $7.9 \cdot 10^{11} \mathrm{~cm}^{-2}$ for the e-beam equivalent dose of $140 \mathrm{krad}\left(\mathrm{SiO}_{2}\right)$ are obtained. These two sets of data show the charging efficiency for the e-beam fluences are approximately ten times that for the $\mathrm{x}$-ray doses, in equivalent rad levels.
The susceptibility of the $\mathrm{SiO}_{2} / \mathrm{Si}_{3} \mathrm{~N}_{4}$ insulation layer to radiation induced charging has been well-studied [14-16]. The large defect densities in the $\mathrm{Si}_{3} \mathrm{~N}_{4}$ and its extremely short carrier recombination lifetimes have resulted in high charge trapping concentrations in the $\mathrm{SiO}_{2} / \mathrm{Si}_{3} \mathrm{~N}_{4}$ interface. One improvement that can be made to reduce the charging in the $\mathrm{SiO}_{2} / \mathrm{Si}_{3} \mathrm{~N}_{4}$ interface is to change the thickness ratio of the two. It has been found that increasing this ratio $\left(\mathrm{SiO}_{2}\right.$ thickness to $\mathrm{Si}_{3} \mathrm{~N}_{4}$ thickness) can significantly reduce the charging sensitivity of this interface [14].

\section{CONCLUSIONS}

Resonant frequency, drive gear angle rotation, and $\mathrm{C}-\mathrm{V}$ measurements can be successfully used to evaluate radiation effects in MEMS actuators. Grounding or operational biasing (with drive signals resulting in motion) of an actuator can prevent most defects caused by irradiation. The microengines tested were radiation operable (driven electrically during irradiation) above the hundreds of Mrad dose range. The radiation sensitivity of grounded comb drives and microengines was approximately $10^{14}$ electrons $/ \mathrm{cm}^{2} \quad(\sim 10$ $\mathrm{Mrad} \mathrm{SiO}_{2}$ ). These radiation sensitivities are far above expected total dose levels in a space environment. The ratio of $\mathrm{SiO}_{2} / \mathrm{Si}_{3} \mathrm{~N}_{4}$ thickness could be changed to reduce the insulation layer's charging sensitivity.

\section{ACKNOWLEDGMENTS}

The authors would like to thank Danelle Tanner, Steve Rodgers, Paiboon Tangyunyong, and Sam Miller for useful technical discussions and to thank Peggy Clews for supplying test parts.

This work was supported by the United States Department of Energy under contract DOE-AC04-94AL85000. Sandia is a multi-program laboratory operated by Sandia Corporation, a Lockheed Martin Company, for the United States Department of Energy.

\section{REFERENCES}

[1] W. C. Tang, "MEMS Applications in Space Exploration," Proc. of SPIE Micromachined Devices and Components III, Vol. 3224, Austin, Sept. 29-39, 1997, pp. 202-211, $0277-786 \mathrm{X} / 97$.

[2] J. H. Comtois, M. A. Michalicek, C.C. Barron, "Fabricating Micro-Instruments in SurfaceMicromachined Poly-crystalline Silicon," Proc. of the $43^{\text {rd }} \quad$ International Instrumentation Symposium, Instrument Society of America, 1997, pp. 169-78.

[3] J. J. Sniegowski and E. J. Garcia, "Microfabricated Actuators and Their Application to Optics," Proceedings SPIE Miniaturized Systems with Micro-Optics and Micromechanics, Vol. 2383, San Jose, CA, Feb. 7-9, 1995 pp. 46-64.

[4] A. R. Knudson, S. Buchner, P. McDonald, W. J. Stapor, A. B. Campbell, K. S. Grabowski, and D. L. Knies, "The Effects of Radiation On MEMS Accelerometers," IEEE Trans. Nucl. Sci. Vol. 43 (6), Dec. 1996. pp. 3122-3126. 
[5] C. I. Lee, A. H. Johnson, W. C. Tang, and C. E. Barnes, "Total Dose Effects on Micr-oelectro-mechanical Systems (MEMS): Accelerometers," IEEE Trans. Nucl. Sci. Vol. 43 (6), Dec. 1996, pp. 3127-3132.

[6] M. S. Rodgers, J. J. Sniegowski, S. L. Miller, C. C. Barron and P. J. McWhorter, "Advanced Micromechanisms in a Multi-level Polysilicon Technology," Proc. of SPIE Micromachined Devices and Components III, Vol. 3224, Austin, Sept. 29-39, 1997, pp. 120-130, 0277-786X/97.

[7] S. L. Miller, J. J. Sniegowski, G. LaVigne and P. J. McWhorter, "Friction in Surface Micromachined Microengines," Proc. of SPIE Smart Electronics and MEMS, Vol. 2722, San Diego, Feb. 28-29, 1996, pp. 197204.

[8] D. M. Tanner, W. M. Miller, W. P. Eaton, L. W. Irwin, K. A. Peterson, M. T. Dugger, D. C. Senft, N. F. Smith, P. Tangyrunyong and S. L. Miller, "The Effect of Frequency on the Lifetime of a Surface Micromachined Microengine Driving a Load," 1998 IEEE International Reliability Physics Symposium, Reno, NV, March 30 - April 2, 1998, pp. 26-35.

[9] S. L. Miller, G. LaVigne, M. S. Rodgers, J. J. Sniegowski, J. P. Walters and P. J. McWhorter "Routes to Failure in Rotating MEMS Devices Experiencing Sliding Friction," Proc. of SPIE Micromachined Devices and Components III, Vol. 3224, Austin, Sept. 29-39, 1997, pp. 24-30, 0277-786X/97.

[10]R. Maboudian and R. T. Howe, "Stiction Reduction Processes for Surface Micromachines," Tribology Leiters 3, 1997, pp. 215-221.

[11]C. Linder, E. Zimmermann and N. F. DeRooij, "Capacitive Polysilicon Resonator with MOS Detection Circuit," Sensors and Actuators A, Vol. 25-27, 1991, pp. 592-595.

[12]H. P. Neff, Jr., Basic Electromagnetic Fields, (C) 1981, Harper \& Row, p.116.

[13]S. A. Campbell, The Science and Engineering of Microelectronic Fabrication, (C) 1996, Oxford University Press, p. 206

[14] J. R. Schwank, S. B. Roeske, D.E. Beutler, D. J. Moreno and M. R. Shaneyfelt, "A Dose Rate Independent pMOS Dosimeter for Space Applications," IEEE Trans. Nucl. Sci., Vol. 43 (6), Dec. 1996, pp. 2671-78.

[15]R. C. Hughes and W. R. Dawes, Jr., "Dual Dielectric Silicon Metal-Oxide-Semiconductor Field-Effect Transistors as Radiation Sensors," J. Appl. Phys, 65 (5), March 1, 1989, pp. 1972-76.

[16]H. E. Boesch, Jr. and C. A. Pennise, "Measurement and Modeling of Radiation Response of Multilayer BESOI Buried Insulators," IEEE Trans. Nucl. Sci., Vol. 41 (6), Dec. 1994, pp. 2322-31. 